\title{
Water adsorption and freeze-thaw resistance of limestone treated with Oxal NK100
}

\author{
Elena Korneeva ${ }^{1, *}$, Anna Babanina ${ }^{2}$, and Yulia Larionova ${ }^{3}$ \\ ${ }^{1}$ Saint Petersburg State University of Architecture and Civil Engineering, 4, 2nd Krasnoarmeyskaya \\ str., 190005, St. Petersburg, Russia \\ ${ }^{2}$ Peter the Great St. Petersburg Polytechnic University, 29, Polytechnicheskaya str., 195251, St. \\ Petersburg, Russia \\ ${ }^{3}$ Moscow State University of Civil Engineering, Yaroslavskoe shosse 26, Moscow, 109377, Russia
}

\begin{abstract}
Natural limestone is subjected to negative impact of external factors, such as rain and low air temperature. One of the ways to improve the properties of limestone is considered in the paper, which is its treatment with Oxal NK100 compound. A review of the literature regarding the problem of durability and the use of limestone is presented. The water absorption and freeze-thaw resistance of the rock was determined experimentally before and after processing with a stone reinforcing compound. The analysis of the obtained data is conducted and conclusions about the effectiveness of the Oxal NK100 composition are drawn.
\end{abstract}

\section{Introduction}

Limestone is a generic term for a variety of rocks containing calcite (calcium carbonate). The origin of limestone is mainly associated with the release of calcium carbonate from sea water by living organisms, which is necessary for the formation of skeletons and shells. In addition, young rocks of limestone are formed with the participation of calcite, which comes as a result of the ancient rocks destruction.

Limestone can be divided into types depending on the conditions of formation. One of them is nummulite limestone. Numulite limestone got its name due to the presence of coinshaped nummulite shells in their composition. Their structure is zoogenic, biomorphic. The texture is undistinctly laminated. The deposits of these limestones are located in Crimea and are mainly developed for wall materials.

Despite its internal strength, limestone belongs to soft rocks, therefore it is subject to weathering. Limestone products begin to deteriorate after 75 years on average. The causes of destruction are high humidity and other external factors. Subsequently, chemical decomposition of minerals and acids dissolved in water occurs. The stone is leached, cracks and cavities begin to form, the strength and stability of the rock reduces. Then water penetrates the pores and the limestone softens.

Preventing the negative influence of external factors on limestone structures is an urgent practical problem. There are various impregnations and gels to improve the characteristics

* Corresponding author: p198320@yandex.ru 
of the stone. The German development of Oxal NK100 is a firming gel, which is used to secure natural stone, plaster and bricks. Its composition allows to use it on mineral and absorbent materials. Its main feature is that it does not contain solvents and hydrophobic additives. In connection with the relevance of studying the mechanical characteristics of limestone, there are more and more published scientific papers related to the study of this stone's strength properties. Frolova Yu.V. and Arakcheeva Ya.A. in their paper consider the correlation between the strength of limestone samples from the Domodedovo open-cast mine under uniaxial compression and their absolute and relative sizes, shape and friction at the contacts between their ends and the loading plates. Borodin I.N. and Abramyan A.K. in their research demonstrate a number of three-dimensional effects arising from the dynamic loading numerical simulation of limestone samples in Hopkinson-Kolsky bars. Various destruction modes of porous limestone samples and the corresponding deformation curves were studied [1-2].

Of special interest is the work of Kondratiev S.A., Rostovtsev V.I., Kulagin O.R. and Sivolap B.B. The study describes the research of limestone's mechanical properties considering the processing of sample's core with accelerated electrons. The ultimate strength under uniaxial loading, static and dynamic elasticity moduli, and Poisson's ratios were determined depending on the dose absorbed by the samples [3]. The ability of limestone to withstand repeated alternate freezing and thawing without visible signs of destruction and without a significant decrease in strength is an extremely important property in the design of cement and concrete. That is why many authors study the behavior of concrete with the addition of limestone for the conditions which are different from normal. Authors Kalashnikov V.I., Suzdaltsev O.V., Moroz M.N., Pausk V.V. presented the assessment results of the freeze-thaw resistance of self-compacting colored, powderactivated carbonate fine-grained concrete with the strength of 140-150 MPa, which is made of microsilica. It is illustratory that the dispersed aggregate, fine-grained aggregate and sand aggregate in high-strength carbonate concrete are obtained from the sifting of grinded limestone. According to the paper of Sivkov S.P. and Savkina S.A., it is shown that the intergration of limestone additive to the composition of white cement in an amount up to 10 wt. \% improves the whiteness of cement and increases its freeze-thaw resistance [4-5].

At the moment, the relevant research topic is the durability of building materials. Such aspects as the safety of structural materials in time, the service life of the material after its treatment with various compositions, as well as after prolonged or short-term impact by various external factors (radiation, heat, prolonged static loading, etc.) are considered [610]. The purpose of this research is to practically confirm the improvement of the limestone's characteristics, such as a decrease in water adsorption and an increase in freezethaw resistance, after being treated with the Oxal NK100 stone-reinforcing compound. In order to achieve this goal, the following tasks were set:

Carry out a comparative test of two limestone samples types (limestone without additives and limestone NK100) in order to obtain water adsorption characteristics at full immersion;

Carry out a comparative test of two limestone samples types (limestone without additives and limestone NK100) to obtain freeze-thaw resistance characteristics;

Draw conclusions about the effectiveness of the gel Oxal NK100 according to the tested samples.

\section{Materials and Methods}

Samples made of nummulite limestone are considered in the research and compared with the same limestone impregnated with Oxal NK100 stone reinforcement. 
The subject of research is Crimean nummulite limestone of natural origin and nummulite limestone treated with Oxal NK100.

The choice of the research subject is due to several reasons:

1. Most of the Crimean historical buildings are made of limestone and sandstone.

2. Currently, there is an urgent need to apply new materials for the restoration of historical architectural objects, which requires an increase in the operational properties that affect the building durability. $2 \mathrm{~mm})$.

The tests were carried out on samples with sizes $a=b=c=50 \mathrm{~mm}$ (with an error of \pm

In accordance with the technical specifications, the samples were marked with color and numbered depending on the test carried out.

In order to obtain operational specifications, the following tests were performed on:

- water adsorption;

- freeze-thaw resistance.

All tests were conducted in accordance with GOST 30629-2011 "Materialy' i izdeliya obliczovochny`e iz gorny`x porod. Metody` ispy`tanij”

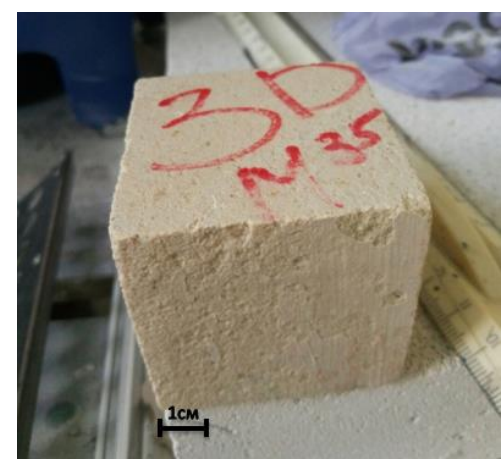

Fig. 1. Limestone test sample.

\section{Experimental determination of water adsorption of untreated limestone samples and samples treated with Oxal NK100}

Water adsorption is determined by comparing the mass of rock samples in a water-saturated state and after drying.

Controls and ancillary equipment:

- bench dial scales according to GOST 29329.

- dessicator electrical cabinet.

- vessel for saturating samples with water.

- brush according to GOST 10597.

The water adsorption of the rock was determined on five cube samples with faces of 40$50 \mathrm{~mm}$ in size. Samples were cleaned with a metal brush from loose particles and dust and dried to constant weight. Samples were weighed after they were completely cooled in air to room temperature.

The samples were placed in a vessel with water at a temperature of $(20 \pm 5){ }^{\circ} \mathrm{C}$ in one row so that the water level in the vessel was above the top of the samples by $20 \mathrm{~mm}$. They were kept in water for 48 hours, removed from the vessel and weighed. 


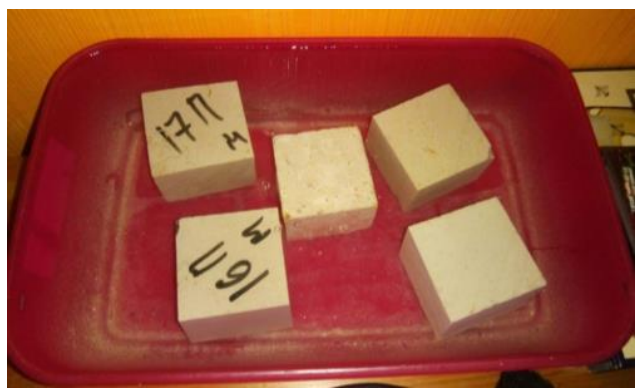

Fig. 2. Samples immersed in a vessel with water.

Thus, the following mass values of the untreated samples were obtained:

Table 1. Untreated samples.

\begin{tabular}{|l|c|c|c|}
\hline № & $\begin{array}{c}\text { Masses of samples (before } \\
\text { drying), g }\end{array}$ & $\begin{array}{c}\text { Masses of samples (with } \\
\text { constant mass after drying), g }\end{array}$ & $\begin{array}{c}\text { Masses of samples (after 48 } \\
\text { hours in the water), g }\end{array}$ \\
\hline 1 & 221.96 & 221.65 & 247.63 \\
\hline 2 & 227.27 & 226.89 & 252.80 \\
\hline 3 & 220.00 & 219.67 & 246.34 \\
\hline 4 & 221.95 & 221.58 & 247.28 \\
\hline 5 & 224.44 & 224.06 & 250.03 \\
\hline
\end{tabular}

Mass values for samples treated with the compound:

Table 2. Treated samples.

\begin{tabular}{|l|c|c|c|}
\hline № & $\begin{array}{c}\text { Masses of samples (before } \\
\text { drying), } g\end{array}$ & $\begin{array}{c}\text { Masses of samples (with } \\
\text { constant mass after drying), } g\end{array}$ & $\begin{array}{c}\text { Masses of samples (after 48 } \\
\text { hours in the water), g }\end{array}$ \\
\hline 1 & 247.95 & 245.35 & 251.61 \\
\hline 2 & 246.43 & 243.86 & 251.37 \\
\hline 3 & 247.19 & 244.76 & 255.74 \\
\hline 4 & 245.70 & 243.19 & 251.54 \\
\hline 5 & 239.12 & 236.00 & 239.69 \\
\hline
\end{tabular}

Water adsorption $\mathrm{W}_{\mathrm{ad}}, \%$ by weight, is calculated according to the following formula:

$$
\mathrm{W}_{\mathrm{ad}}=\frac{\mathrm{m}_{1}-\mathrm{m}}{\mathrm{m}} \cdot 100
$$

Where $\mathrm{m}_{1}$ is the mass of the sample in a water saturated state, $\mathrm{kg}$;

$\mathrm{m}$ - sample mass in a dry state, $\mathrm{kg}$.

Water absorption is calculated as the arithmetic average of the results after determining the water adsorption of five rock samples.

Untreated samples:

$$
\begin{gathered}
\mathrm{W}_{\mathrm{ad} 1}=\frac{\mathrm{m}_{1}-\mathrm{m}}{\mathrm{m}} \cdot 100=\frac{247.63-221.65}{221.65} \cdot 100=11.721 \% \\
\mathrm{~W}_{\mathrm{ad} 2}=\frac{\mathrm{m}_{1}-\mathrm{m}}{\mathrm{m}} \cdot 100=\frac{252.80-226.89}{226.89} \cdot 100=11.42 \% \\
\mathrm{~W}_{\mathrm{ad} 3}=\frac{\mathrm{m}_{1}-\mathrm{m}}{\mathrm{m}} \cdot 100=\frac{246.34-219.67}{219.67} \cdot 100=12.141 \%
\end{gathered}
$$




$$
\begin{aligned}
& \mathrm{W}_{\mathrm{ad} 4}=\frac{\mathrm{m}_{1}-\mathrm{m}}{\mathrm{m}} \cdot 100=\frac{247.28-221.58}{221.58} \cdot 100=11.599 \% \\
& \mathrm{~W}_{\mathrm{ad} 5}=\frac{\mathrm{m}_{1}-\mathrm{m}}{\mathrm{m}} \cdot 100=\frac{250.03-224.06}{224.06} \cdot 100=11.591 \% \\
& \mathrm{~W}_{\mathrm{ad} \text { total }}=\frac{\mathrm{W}_{\mathrm{ad} 1}+\mathrm{W}_{\mathrm{ad} 2}+\mathrm{W}_{\mathrm{ad} 3}+\mathrm{W}_{\mathrm{ad} 4}+\mathrm{W}_{\mathrm{ad} 5}}{5}= \\
& =\frac{11.721 \%+11.42 \%+12.141 \%+11.599 \%+11.591 \%}{5}=11.69 \%
\end{aligned}
$$

Samples treated with NK100:

$$
\begin{aligned}
\mathrm{W}_{\mathrm{ad} 1} & =\frac{\mathrm{m}_{1}-\mathrm{m}}{\mathrm{m}} \cdot 100=\frac{251.61-245.35}{245.35} \cdot 100=2.551 \% \\
\mathrm{~W}_{\mathrm{ad} 2} & =\frac{\mathrm{m}_{1}-\mathrm{m}}{\mathrm{m}} \cdot 100=\frac{251.37-243.86}{243.86} \cdot 100=3.08 \% \\
\mathrm{~W}_{\mathrm{ad} 3} & =\frac{\mathrm{m}_{1}-\mathrm{m}}{\mathrm{m}} \cdot 100=\frac{255.74-244.76}{244.76} \cdot 100=4.486 \% \\
\mathrm{~W}_{\mathrm{ad} 4} & =\frac{\mathrm{m}_{1}-\mathrm{m}}{\mathrm{m}} \cdot 100=\frac{251.54-243.19}{243.19} \cdot 100=3.434 \% \\
\mathrm{~W}_{\mathrm{ad} 5} & =\frac{\mathrm{m}_{1}-\mathrm{m}}{\mathrm{m}} \cdot 100=\frac{239.69-236.00}{236.00} \cdot 100=1.564 \% \\
\quad \mathrm{~W}_{\mathrm{ad} \text { total }}= & \frac{\mathrm{W}_{\mathrm{ad} 1}+\mathrm{W}_{\mathrm{ad} 2}+\mathrm{W}_{\mathrm{ad} 3}+\mathrm{W}_{\mathrm{ad} 4}+\mathrm{W}_{\mathrm{ad} 5}}{5} \\
= & \frac{2.551 \%+3.08 \%+4.486 \%+3.434 \%+1.564 \%}{5}=3.023 \%
\end{aligned}
$$

\section{Experimental freeze-thaw resistance determination of untreated limestone samples and samples treated with the Oxal NK100 compound}

The method's root consists in determining the loss of rock strength after a specified cycle amount, each cycle includes alternate freezing and thawing, compared with the strength of a water-saturated sample.

Controls and ancillary equipment:

Freezing compartment which allows to achieve and maintain a temperature of minus (20 $\pm 2{ }^{\circ} \mathrm{C}$;

Dessicator electrical cabinet.

Hydraulic press with a maximum force up to $500 \mathrm{kN}$ according to GOST 28840;

Bath with a device for maintaining the temperature $(20 \pm 2){ }^{\circ} \mathrm{C}$ for saturating the samples with water and their thawing;

\subsection{Sample containers}

Five rock samples were made for each test. The samples were placed in a bath on the grate in one row and filled with water so that the water level was above the top of the samples by $20 \mathrm{~mm}$. The samples were kept in water for 48 hours, after which they were removed from the bath. The samples were installed in the freezer container so that the distance between 
the samples, the walls of the container and the overlying racks was at least $30 \mathrm{~mm}$. The beginning of the freezing was considered the moment when the temperature in the chamber was set at minus $18{ }^{\circ} \mathrm{C}$. The samples were kept in the chamber for 4 hours at a temperature of minus $(20 \pm 2){ }^{\circ} \mathrm{C}$, after which the samples were put into the bath and kept in it until complete thawing. Then the cycle of freezing and thawing was repeated.

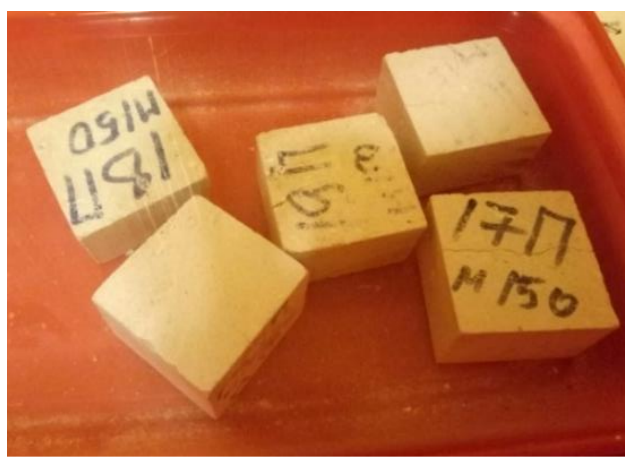

Fig. 3. Freezing in the compartment.

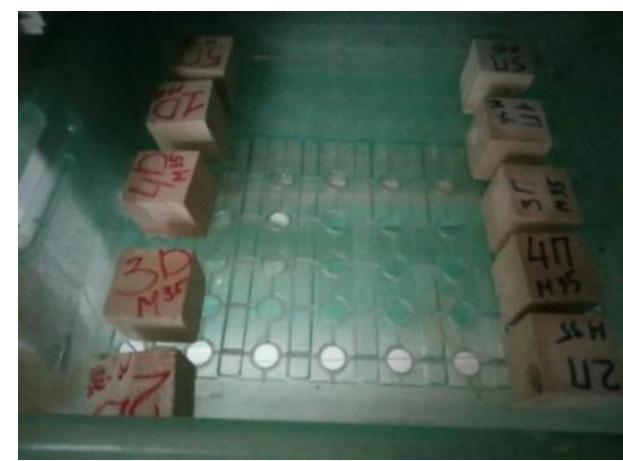

Fig. 4. Thawing in vessels with water.

After $15 ; 25 ; 35 ; 50$ alternate freezing and thawing cycles five water-saturated samples were subjected to the compression test.

Strength loss of the samples $\Delta \mathrm{R}, \%$ is calculated according to the following formula:

$$
\Delta \mathrm{R}=\frac{\mathrm{R}_{\mathrm{c}}^{\text {sat }}-\mathrm{R}_{\mathrm{c}}^{\mathrm{f}}}{\mathrm{R}_{\mathrm{c}}^{\text {sat }}} \cdot 100 \%
$$

where $\mathrm{R}_{\mathrm{c}}^{\mathrm{sat}}$ is arithmetic mean compressive strength value of samples in a watersaturated state, $\mathrm{MPa}\left(\mathrm{kgf} / \mathrm{cm}^{2}\right)$;

$\mathrm{R}_{\mathrm{c}}^{\mathrm{f}}$ - arithmetic mean compressive strength value of samples after freeze-thaw resistance test, $\mathrm{MPa}\left(\mathrm{kgf} / \mathrm{cm}^{2}\right)$.

The strength loss of the samples is calculated as the arithmetic mean of the test results of five samples. The rock meets the appropriate grade for freeze-thaw resistance, if no cracks, chippings or peelings appeared on the samples during external examination, and the compressive strength loss after a set cycle number of alternate freezing and thawing does not exceed $20 \%$.

Table 3. Ultimate strength (15 cycles), MPa.

\begin{tabular}{|l|c|c|c|c|c|c|}
\hline \multicolumn{1}{|c|}{ Sample № } & 1 & 2 & 3 & 4 & 5 & $\mathrm{R}_{\mathrm{c}, \mathrm{MPa}}$ \\
\hline Limestone & 9.6 & 10.9 & 11.6 & 9.1 & 8.9 & 10.02 \\
\hline Limestone NK100 & 20.6 & 22.3 & 23.4 & 12.7 & 15.4 & 18.88 \\
\hline
\end{tabular}

Table 4. Ultimate strength ( 25 cycles), MPa.

\begin{tabular}{|l|c|c|c|c|c|c|}
\hline \multicolumn{1}{|c|}{ Sample № } & 1 & 2 & 3 & 4 & 5 & $\mathrm{R}_{\mathrm{c}, \mathrm{MPa}}$ \\
\hline Lame & & & & & & \\
\hline Limestone & 9.4 & 7.4 & 11.1 & 13.0 & 12.8 & 10.74 \\
\hline
\end{tabular}

Untreated limestone Samples showed visible defects after 30 cycles of alternate freezing and thawing. 


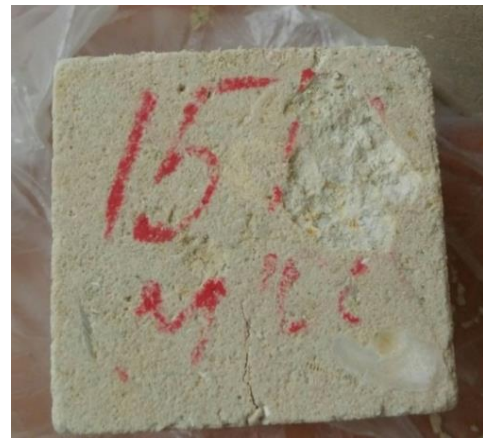

Fig. 5. Cracks on the untreated sample treatment.

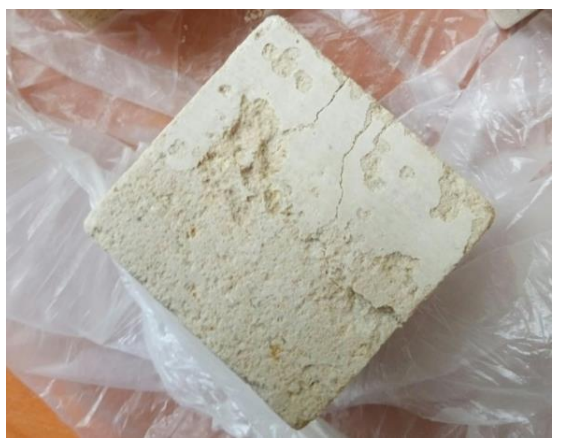

Fig. 6. Cracks and peelings on the untreated sample.

Table 5. Ultimate strength ( 35 cycles), MPa.

\begin{tabular}{|l|c|c|c|c|c|c|}
\hline Sample № & 1 & 2 & 3 & 4 & 5 & $\mathrm{R}_{\mathrm{c}, \mathrm{MPa}}$ \\
Name & & & & & & \\
\hline Limestone NK100 & 23.4 & 33.7 & 5.0 & 28.1 & 48.9 & 27.82 \\
\hline
\end{tabular}

Table 6. Ultimate strength (50 cycles), MPa.

\begin{tabular}{|l|c|c|c|c|c|c|}
\hline Sample № & 1 & 2 & 3 & 4 & 5 & $\mathrm{R}_{\mathrm{c}, \mathrm{MPa}}$ \\
\hline Name & 8.6 & 12.3 & 10.1 & 12.2 & 14.0 & 11.44 \\
\hline
\end{tabular}

\section{Results and discussion}

The results of the experiments and calculations made to determine the water adsorption of the rock can be represented in a graph:

\section{Water adsorption}

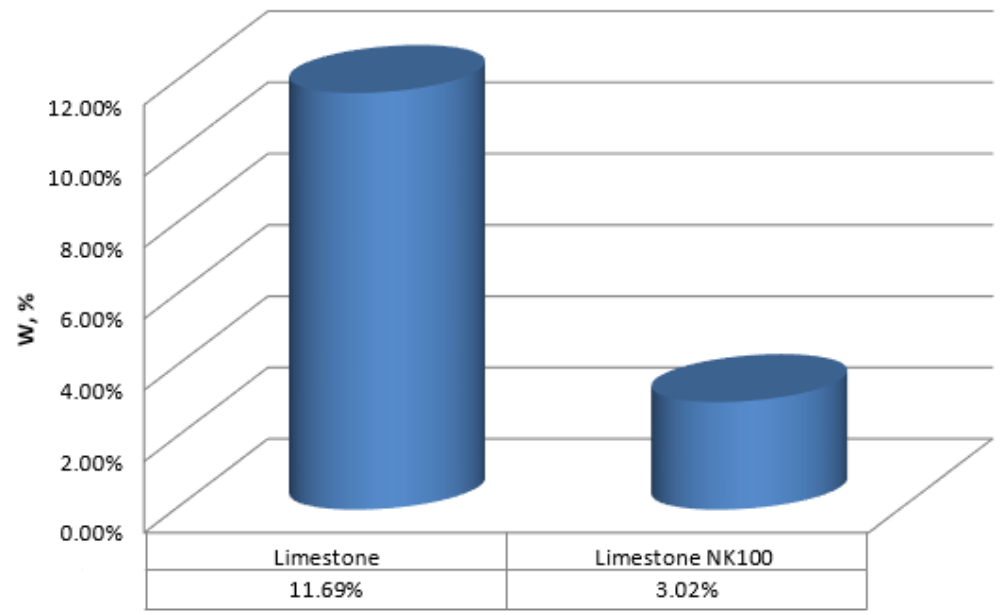

Fig. 1. The results of the experiments and calculations. 
Comparing the obtained results, it can be concluded that the water adsorption of limestone treated with Oxal NK100 stone-reinforcing material is $3.023 \%$, and the water absorption of untreated limestone is $11.69 \%$. Water adsorption is reduced by almost 4 times.

The results of the experiments and calculations made to determine the freeze-thaw resistance of the rock can be represented in a following comparative graph:

\section{Comparative graph of the change in strength after each cycle of alternate freezing and thawing}

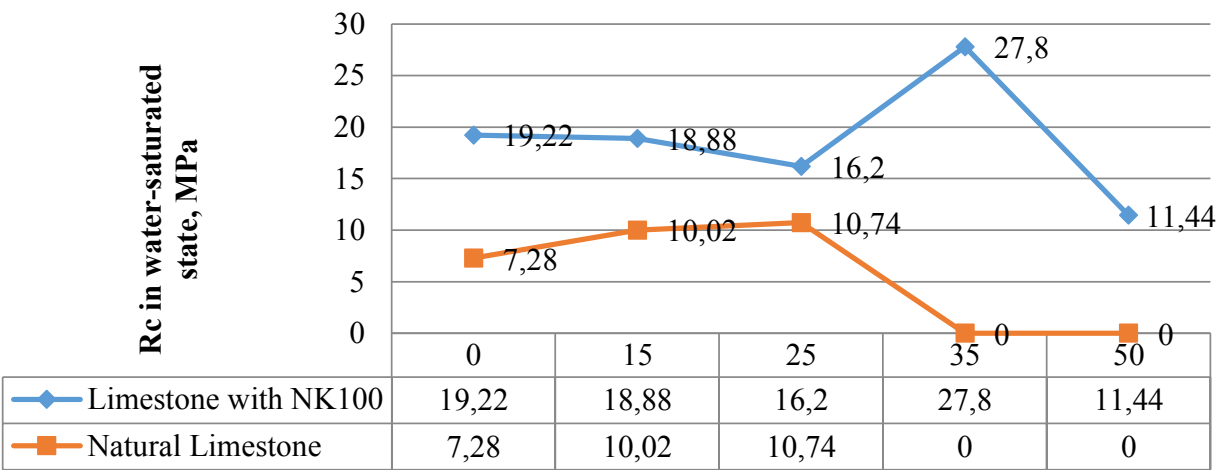

Fig. 2. The results of the experiments and calculations.

The graph shows that untreated limestone withstands only 25 cycles, and limestone treated with a stone-strengthening compound significantly loses its strength after 35 cycles of alternate freezing and thawing, but withstands up to 50 cycles of freeze-thaw resistance. Therefore, according to the test results, it can be concluded that the limestone treated with Oxal NK100 material withstands twice as many cycles of alternate freezing and thawing.

\section{Conclusions}

As a result of studying performance properties that affect the structural durability, the comparative tests showed the efficiency of the Oxal NK100 stone reinforcing material. The following conclusions were made based on the research results:

Stone reinforcement material improves the stone's properties by 4 times, reducing the water adsorption index, which indicates the effectiveness of the Oxal NK100 compound.

Limestone treated with a stone reinforcing compound withstands twice as many cycles of alternate freezing and thawing, according to the results of a comparative freeze-thaw resistance test.

\section{References}

1. Y.V. Frolova., Y.A. Arakcheeva, Inzhenernaya geologiya 1, 56-67 (2012)

2. I.N. Borodin, A.K. Abramyan, Vychislitel'naya mekhanika sploshnyh sred 10(3), 341350 (2017)

3. S.A. Kondrat'ev, V.I. Rostovcev, O.R. Kulagin, B.B. Sivolap, Interehkspo geo-sibir' 2(3), 142-146 (2016) 
4. V.I. Kalashnikov, O.V. Suzdal'cev, M.N. Moroz, V.V. Pausk, Stroitel'nye materialy 3, 16-19 (2015)

5. S.P. Sivkov, S.A. Savkina, AlitInform: Cement. Beton. Suhie smesi 5-6, 91-97 (2011)

6. O.B. Nastich, V.V. Hvorost, Vestnik krivorozhskogo nacional'nogo universiteta 4(33), 29-32 (2013)

7. S. Pal'm, K. Myuller, Cement i ego primenenie 2, 36-39 (2013)

8. L.Z. Usmanova, D.Z. Usmanova, Tekhnika i tekhnologiya silikatov 23(1), 19-22 (2016)

9. V.A. P'yachev, K.S. Ishutin, Cement i ego primenenie 1, 59-60 (2009)

10. M.G. Smerdov, E.O. Selivanova, Innovacionnyj transport 2(16), 60-63 (2015)

11. O.M. Smirnova, International Journal of Civil Engineering and Technology, 9(8), 1733-1740 (2018)

12. A.A. Heravi, O. Smirnova, V. Mechtcherine, RILEM Bookseries, 15, 266-274 (2018) 